\title{
Assessing the Disease Severity of Alternaria Blight of Rapeseed-Mustard in Jammu Province of J\&K and Screening of Germplasm against the Disease
}

\author{
Baby Summuna $^{1 *}$, Sachin Gupta ${ }^{2}$ and P.A. Sheikh ${ }^{1}$ \\ ${ }^{1}$ Division of Plant Pathology, SKUAST-Kashmir, India \\ ${ }^{2}$ Division of Plant Pathology, SKUAST-Jammu, India \\ *Corresponding author
}

\begin{abstract}
A B S T R A C T
Keywords

Alternaria blight, Disease

severity, Germplasm

screening, Rapeseed-

mustard, Survey

Article Info

Accepted:

10 October 2018

Available Online:

10 November 2018

Alternaria blight of rapeseed-mustard caused by Alternaria brassicae (Berk) Sacc. is one of the important diseases of rapeseed-mustard in Jammu division of J\&K. Survey conducted revealed that maximum disease severity in leaves at 75 DAS and 100 DAS was 38.53 and 49.71 per cent and in pods was 32.72 and 44.97 per cent, respectively, observed in District Reasi. However, Samba recorded least disease severity at 75 and 100 DAS with 20.40 and 32.97 per cent in leaves and 11.30 and 23.42 per cent in pods. Of the twenty seven different genotypes screened for their reaction against Alternaria blight, two genotypes viz. RH-8113 and PC-5 showed moderate resistance, four genotypes viz. GM-3, RH-1359, RH-819 and JM-1 were found to be moderately susceptible, eighteen genotypes viz. Geeta, PusaBahar, Rohini, RH-30, Shivani, RH-781, RGN-13, GM-2, RRN-505, Krishna, GM-1, PusaJaganath, Vaibhav, RSPN-602, DGS-1, RSPN-25, RSPN-2 and RSPR-69 recorded susceptible reaction. However, three genotypes viz. Kranti, Varuna and CS-54 were found to be highly susceptible.

\section{Introduction}

In India, oilseeds constitute the second largest agricultural commodity after cereals and account for nearly 5 per cent of gross national product (GNP) and 10 per cent of the value of all agricultural products (Saharan and Mehta, 2002). Oilseeds are mainly grown for edible oils, spices, condiments and fodder for livestock. In Jammu and Kashmir state, the total area under oilseeds is 63.27 thousand ha, out of which Jammu division has a share of 16.38 thousand ha and the total production of the state is 535q (Anonymous, 2008). Rapeseed-mustard is one of the most

important oilseed crops and occupies a prominent place both in terms of area and production. It is a group of crops that contributes 32 per cent of total oilseed production in India and is the second largest indigenous oilseed crop.

Out of $73.09 \mathrm{~m}$ tons of estimated rapeseedmustard produced over $37.00 \mathrm{~m}$ ha in the world, India produces $7.90 \mathrm{~m}$ tons from 6.70 $\mathrm{m}$ ha with $1188 \mathrm{~kg} / \mathrm{ha}$ productivity (Anonymous, 2014). It is projected that by 2020, 41 per cent (14 million tons) of total demand for oilseed in India will be met by mustard alone (Kalyan et al., 2007).
\end{abstract}


Despite the fact that India is one of the leading oilseed producing countries of the world, it is not able to meet the edible oil requirement for its vast population. Among different constraints in the production of rapeseedmustard which is an important oilseed crop, diseases are the most important limiting factors which restrict the cultivation and decrease the productivity of these crops. In Indian context, fungal diseases are rated as one of the most important factor contributing to yield losses in oilseed crops (Anita and Gowthaman, 2003).

More than thirty diseases are known to occur on Brassica crops in India. These include Alternaria blight, white rust, downy mildew, powdery mildew etc. Among these, Alternaria blight caused by Alternaria brassicae (Berk.) Sacc. has been reported from all the continents of the world affecting most cruciferous crops and is one among the important diseases of rapeseed-mustard causing severe yield losses with no proven source of transferable resistance in any of the hosts (Meena et al., 2010). The disease occurs regularly year after year during cropping season in severe form and infects both leaves as well as siliquae thereby resulting in reduction of quantity and quality of the crop (Saharan, 1992).

A. brassicae, infects the aerial plant parts causing cholorotic and necrotic foliar lesions (Verma and Saharan, 1994).Besides quantitative loss in yield, the quality of seed i.e., seed size, colour and germination are also drastically affected due to this disease (Randhawa and Aulakh, 1981). Yield losses up to 71.4 per cent (Saharan et al., 2003) and losses in oil content to the tune of 14.6-36 per cent have been reported (Ansari et al., 1988).

Management of Alternaria blight is very difficult and requires frequent fungicidal sprays. Although, crop rotation helps in avoiding the soil-borne primary inoculum but is practically not feasible. Keeping in view, the environmental hazards associated with the use of chemicals, cultivation of varieties resistant to the disease is a better option for its management. Keeping in view, the environmental hazards associated with the use of chemicals, cultivation of varieties resistant to the disease is a better option for its management.

\section{Materials and Methods}

Field experiments of the present investigation on Alternaria blight of rapeseed-mustard were conducted at the University Research Farm, Chatha. The laboratory experiments were carried out in the Division of Plant Pathology. The detailed account of materials and methodology adopted is as follows:

\section{Survey and Surveillance}

Survey of rapeseed-mustard growing area of Jammu Division was conducted to monitor the prevalence and status of Alternaria blight for which five districts were selected on the basis of their area under the cultivation of the crop. Three villages in each district were identified and five fields of every village were marked for assaying the status of the disease. The disease was recorded using quadrant $\left(1 \mathrm{~m}^{2}\right)$ at 4-5 spots in each field. Randomly five plants were selected and tagged for taking observations.

Five leaves and five pods per plant were taken from different plant parts for scoring the disease intensity. Observations for disease severity were taken at 75 and 100 days after sowing. The overall disease scoring was done at 0-6 rating scale on the basis of disease assessment key for Alternaria blight in rapeseed-mustard (Conn et al., 1990) (Fig. 1).

Disease severity was calculated using the following formula: 
Sum of all disease ratings Disease severity $(\%)=$

Total number of ratings $x$ Maximum disease rating

\section{Isolation, purification and maintenance of} pathogen

Different infected plant parts viz. leaves, pods and stems of infected rapeseed-mustard plants were collected in paper bags and brought to the laboratory for further investigation.

The bits of diseased portion of infected plant parts along with healthy portion were cut into bits of 8-10 mm, surface sterilized with sodium hypochlorite solution $(0.1 \%)$ for 30 seconds, washed thrice with sterilized distilled water and thereafter three-four bits were placed in each petriplate containing Potato Dextrose Agar (PDA) medium.

\section{Identification, purification maintenance of pathogen}

The inoculated plates were incubated in BOD incubator at $22 \pm 2^{\circ} \mathrm{C}$ and regularly monitored for the fungal growth. The fungus was identified on the basis of morpho-cultural characteristics (Barnett and Hunter, 1972).

Pure culture of the fungus was obtained by single hyphal tip method (Rather, 2005). For confirmation of the identity of fungus, the slants of pure culture were sent to National Bureau of Agriculturally Important Microbes (NBAIM), Mau. Sub culturing of pure slants of the fungus was done regularly at 15 day intervals.

After every three sub-culturing, the spore suspension of Alternaria brassicae was sprayed on live hosts and fresh isolations were made from artificially inoculated diseased plant parts in order to maintain the viability of spores.

\section{Preparation of spore suspension}

For inoculation, spore suspension was prepared from freshly developed conidial growth using sterile distilled water and then strained through muslin cloth. The spore concentration was adjusted to $1 \times 10^{5}$ conidia/ml distilled water using hemocytometer. The plants were sprayed with freshly prepared spore suspension using an atomizer (Vishunavat and Kolte, 2008).

\section{Screening of germplasm}

Germplasm for screening of rapeseed-mustard against Alternaria blight was obtained from Directorate of Rapeseed-Mustard Research (DRMR), Bharatpur and was raised in triplicate in rows each of $3 \mathrm{~m}$ length with a susceptible check Varuna after every two test rows. Experimental field where rapeseedmustard was grown during previous years was used for the present investigation. To create maximum disease pressure in the field, repeated inoculations at 35, 50 and 65 Days After Sowing (DAS) of spore suspension as discussed in 2.3.1 on the rapeseed-mustard plants were given and higher dose $(80 \mathrm{~kg} / \mathrm{ha})$ of nitrogen was applied. The crop spacing used was $30 \times 10 \mathrm{~cm}$ following standard package of practices (Anonymous, 2007). Randomly five plants from each row were selected and tagged for taking observations for initial appearance of disease symptoms and the disease severity at 75 and 100 days after sowing as discussed in 2.1.

\section{Results and Discussion}

\section{Survey and surveillance}

To assess the disease severity of Alternaria blight of rapeseed-mustard in different districts of Jammu Division, extensive periodic surveys were conducted during Rabi season at different villages of District Jammu, 
Kathua, Samba, Reasi and Udhampur. The data presented in Table 1 revealed that the disease was encountered in all the locations surveyed at 75 Days after sowing (DAS) and 100 DAS. The maximum disease severity observed in leaves was 38.53 and 49.71 per cent and in pods was 32.72 and 44.97 per cent at 75 and 100 DAS respectively reported from District Reasi followed by Udhampur $(49.54 \%$ in leaves and $37.68 \%$ in pods), Jammu (40.36\% in leaves and $28.73 \%$ in pods) and Kathua $34.54 \%$ in leaves and $31.24 \%$ in pods) districts at 100 DAS. However, Samba recorded minimum disease severity of 20.40 and 32.97 per cent in leaves and 11.30 and 23.42 per cent in pods at 75 and 100 DAS respectively.

\section{Identity of the pathogen}

The fungal culture submitted to NBAIM, Mau was identified as Alternaria brassicae and the culture has been deposited in Culture Collection Bank of NBAIM vide Accession Number NAIMCC-F-02179.

\section{Screening of germplasm}

Trial for screening and evaluation of rapeseedmustard germplasm under Jammu conditions was laid during Rabi season at University Research Farm, Chatha. Twenty seven different genotypes of rapeseed-mustard germplasm were sown to test their reaction against Alternaria blight. Leaves and pods of the genotypes under test were scored for disease severity at 75 and 100 DAS using the scale proposed by (Conn et al., 1990). Of the germplasm tested, two genotypes viz. RH8113 and PC-5 showed moderate resistance at 75 and 100 DAS (>10-20\% disease severity), four genotypes viz. GM-3, RH-1359, RH-819 and JM-1 were found to be moderately susceptible (>20-30\% disease severity) while eighteen genotypes viz. Geeta, PusaBahar, Rohini, RH-30, Shivani, RH-781, RGN-13,
GM-2, RRN-505, Krishna, GM-1, PusaJaganath, Vaibhav, RSPN-602, DGS-1, RSPN-25, RSPN-2 and RSPR-69 were found to be susceptible recording a disease severity ranging from 30 to 50 per cent in leaves and pods at 75 and 100 DAS. Three genotypes viz. Kranti, Varuna and CS-54 were found to be highly susceptible to Alternaria blight recording a disease severity of more than 50 per cent at both 75 and 100 DAS.

Extensive survey of rapeseed-mustard growing areas of Jammu Division of Jammu and Kashmir was conducted to monitor the prevalence and severity of Alternaria blight. Survey was conducted in fifteen villages of five different districts and observations on disease severity were recorded at 75 and 100 DAS on leaves as well as pods of rapeseedmustard. Perusal of data in Table 1 showed that the disease was observed in all the locations with varying ranges at both the stages of observation. Maximum disease severity at 100 DAS was recorded in Reasi (49.71\% in leaves and $44.97 \%$ in pods) followed by Udhampur (49.54\% in leaves and $37.68 \%$ in pods), Jammu (40.36\% in leaves and $28.73 \%$ in pods) and Kathua (34.54\% in leaves and $31.24 \%$ in pods). The least affected district was Samba $(32.97 \%$ in leaves and $23.42 \%$ in pods).

In the present studies, disease severity ranging from 32.42 to 54.94 per cent in leaves and 21.54 to 46.98 per cent in pods was recorded from different districts of Jammu division. Losses due to this disease have been reported from India and world by different workers. Kolte (1985) reported 10-75 per cent losses in yield of oil yielding crops from India. The seed production of Brassicas has been reported to be greatly reduced by the attack of this disease which invades siliquae and penetrate the seeds besides damaging the assimilatory tissues of the leaves and stem (Bains and Tewari, 1986). 


\begin{tabular}{|c|c|c|c|c|}
\hline \multirow{3}{*}{ Location } & \multicolumn{4}{|c|}{ Per cent disease severity } \\
\hline & \multicolumn{2}{|c|}{ Leaf } & \multicolumn{2}{|c|}{ Pod } \\
\hline & 75 DAS & 100 DAS & 75 DAS & 100 DAS \\
\hline \multicolumn{5}{|l|}{ Jammu } \\
\hline R.S. Pura & 23.44 & 36.28 & 13.04 & 22.84 \\
\hline Akhnoor & 32.84 & 41.46 & 23.62 & 30.64 \\
\hline Chatha & 34.24 & 43.36 & 22.72 & 32.72 \\
\hline Range & $23.44-34.24$ & $36.28-43.36$ & $13.04-23.62$ & $22.84-32.72$ \\
\hline Mean \pm S.E.(m) & $30.17 \pm 0.544$ & $40.36 \pm 0.431$ & $19.79 \pm 0.411$ & $28.73 \pm 0.977$ \\
\hline \multicolumn{5}{|l|}{ Kathua } \\
\hline Chadwal & 23.30 & 32.42 & 12.32 & 21.84 \\
\hline Nagri & 20.24 & 38.68 & 11.20 & 35.90 \\
\hline Jarai & 20.26 & 32.54 & 11.92 & 36.00 \\
\hline Range & 20.24-23.30 & $32.42-38.68$ & $11.20-12.32$ & $21.84-36.00$ \\
\hline Mean \pm S.E.(m) & $21.26 \pm 0.384$ & $34.54 \pm 0.764$ & $11.81 \pm 0.208$ & $31.24 \pm 0.272$ \\
\hline \multicolumn{5}{|l|}{ Samba } \\
\hline Nud & 20.94 & 34.28 & 10.08 & 21.54 \\
\hline Banglarh & 21.52 & 30.80 & 12.04 & 22.82 \\
\hline Sumb & 18.74 & 33.84 & 11.80 & 25.92 \\
\hline Range & $18.74-21.52$ & $30.80-34.28$ & $10.08-12.04$ & $21.54-25.92$ \\
\hline Mean \pm S.E.(m) & $20.40 \pm 0.268$ & $32.97 \pm 0.656$ & $11.30 \pm 0.161$ & $23.42 \pm 0.556$ \\
\hline \multicolumn{5}{|l|}{ Reasi } \\
\hline SirlaBhaga & 36.94 & 43.48 & 27.60 & 42.86 \\
\hline Gran Morh & 40.62 & 54.94 & 31.68 & 46.98 \\
\hline Seela & 38.04 & 50.72 & 38.89 & 45.08 \\
\hline Range & $36.94-40.62$ & $43.48-54.94$ & $27.60-38.89$ & $42.86-46.98$ \\
\hline Mean \pm S.E.(m) & $38.53 \pm 0.231$ & $49.71 \pm 0.777$ & $32.72 \pm 0.182$ & $44.97 \pm 0.228$ \\
\hline \multicolumn{5}{|l|}{ Udhampur } \\
\hline Chari Suwail & 32.60 & 49.84 & 22.02 & 36.10 \\
\hline SialSallan & 34.50 & 50.94 & 21.86 & 39.96 \\
\hline Battalwalian & 35.80 & 47.86 & 20.20 & 36.98 \\
\hline Range & $32.60-35.80$ & $47.86-50.94$ & $20.02-22.02$ & $36.10-39.96$ \\
\hline Mean \pm S.E.(m) & $34.30 \pm 0.453$ & $49.54 \pm 0.729$ & $21.36 \pm 0.193$ & $37.68 \pm 0.235$ \\
\hline Overall range & $18.74-40.62$ & $32.42-54.94$ & $11.20-38.89$ & $21.54-46.98$ \\
\hline $\begin{array}{l}\text { Grand mean } \pm \\
\text { S.E.(m) }\end{array}$ & $28.93 \pm 0.376$ & $41.42 \pm 0.671$ & $19.39 \pm 0.231$ & $33.20 \pm 0.454$ \\
\hline
\end{tabular}




\begin{tabular}{|c|c|c|c|c|c|c|c|}
\hline \multirow{3}{*}{ Germplasm } & \multirow{3}{*}{$\begin{array}{c}\text { Initial } \\
\text { appearance } \\
\text { of disease } \\
\text { (DAS) }\end{array}$} & \multicolumn{6}{|c|}{ Per cent disease severity } \\
\hline & & \multicolumn{3}{|c|}{ Leaves } & \multicolumn{3}{|c|}{ Pods } \\
\hline & & $\begin{array}{c}75 \\
\text { DAS }\end{array}$ & $\begin{array}{c}100 \\
\text { DAS }\end{array}$ & Reaction & $\begin{array}{c}75 \\
\text { DAS }\end{array}$ & $\begin{array}{c}100 \\
\text { DAS }\end{array}$ & Reaction \\
\hline Geeta & 45 & 14.0 & 39.1 & $\mathrm{~S}$ & 11.9 & 31.8 & $\mathrm{~S}$ \\
\hline GM-3 & 50 & 12.2 & 28.2 & MS & 7.5 & 22.1 & MS \\
\hline RH-1359 & 45 & 11.7 & 23.5 & MS & 10.7 & 20.7 & MS \\
\hline Kranti & 42 & 35.7 & 60.5 & HS & 23.2 & 56.3 & HS \\
\hline PusaBahar & 50 & 25.4 & 38.1 & $\mathrm{~S}$ & 24.2 & 35.5 & $\mathrm{~S}$ \\
\hline RH-819 & 48 & 16.1 & 28.2 & MS & 19.5 & 29.2 & MS \\
\hline Rohini & 50 & 24.9 & 42.2 & S & 24.2 & 37.7 & S \\
\hline RH-30 & 46 & 28.7 & 47.4 & $\mathrm{~S}$ & 24.7 & 37.1 & S \\
\hline Shivani & 49 & 29.5 & 46.7 & S & 23.3 & 39.8 & S \\
\hline RH-781 & 43 & 27.1 & 48.7 & S & 23.1 & 37.5 & $\mathrm{~S}$ \\
\hline Varuna & 40 & 38.4 & 62.3 & HS & 35.6 & 54.2 & HS \\
\hline RGN-13 & 50 & 31.7 & 48.4 & S & 14.3 & 38.3 & $\mathrm{~S}$ \\
\hline GM-2 & 51 & 27.2 & 40.5 & $\mathrm{~S}$ & 15.4 & 37.9 & $\mathrm{~S}$ \\
\hline CS-54 & 53 & 26.9 & 59.2 & HS & 18.5 & 50.3 & HS \\
\hline JM-1 & 50 & 12.2 & 28.8 & MS & 10.2 & 22.3 & MS \\
\hline RRN-505 & 48 & 20.7 & 35.3 & $\mathrm{~S}$ & 15.3 & 31.6 & $\mathrm{~S}$ \\
\hline Krishna & 48 & 28.5 & 40.3 & $\mathrm{~S}$ & 13.9 & 36.7 & $\mathrm{~S}$ \\
\hline RH-8113 & 57 & 8.5 & 18.2 & MR & 7.3 & 13.1 & MR \\
\hline GM-1 & 50 & 27.1 & 45.5 & $\mathrm{~S}$ & 23.2 & 36.4 & $\mathrm{~S}$ \\
\hline PusaJaganath & 49 & 28.7 & 46.2 & $\mathrm{~S}$ & 15.1 & 32.7 & $\mathrm{~S}$ \\
\hline Vaibhav & 51 & 28.3 & 39.7 & $\mathrm{~S}$ & 18.8 & 35.2 & $\mathrm{~S}$ \\
\hline RSPN-602 & 55 & 29.0 & 47.8 & $\mathrm{~S}$ & 25.5 & 37.4 & $\mathrm{~S}$ \\
\hline PC-5 & 58 & 6.9 & 18.2 & MR & 5.2 & 13.5 & MR \\
\hline DGS-1 & 50 & 29.2 & 46.9 & $\mathrm{~S}$ & 15.7 & 33.4 & $\mathrm{~S}$ \\
\hline RSPN-25 & 52 & 27.6 & 48.7 & $\mathrm{~S}$ & 10.8 & 32.5 & $\mathrm{~S}$ \\
\hline RSPN-2 & 50 & 26.4 & 43.1 & S & 19.9 & 35.5 & $\mathrm{~S}$ \\
\hline RSPR-69 & 52 & 29.8 & 45.5 & $\mathrm{~S}$ & 20.2 & 34.7 & $\mathrm{~S}$ \\
\hline
\end{tabular}


Fig.1 Disease assessment key for Alternaria Blight in rapeseed-mustard [12]

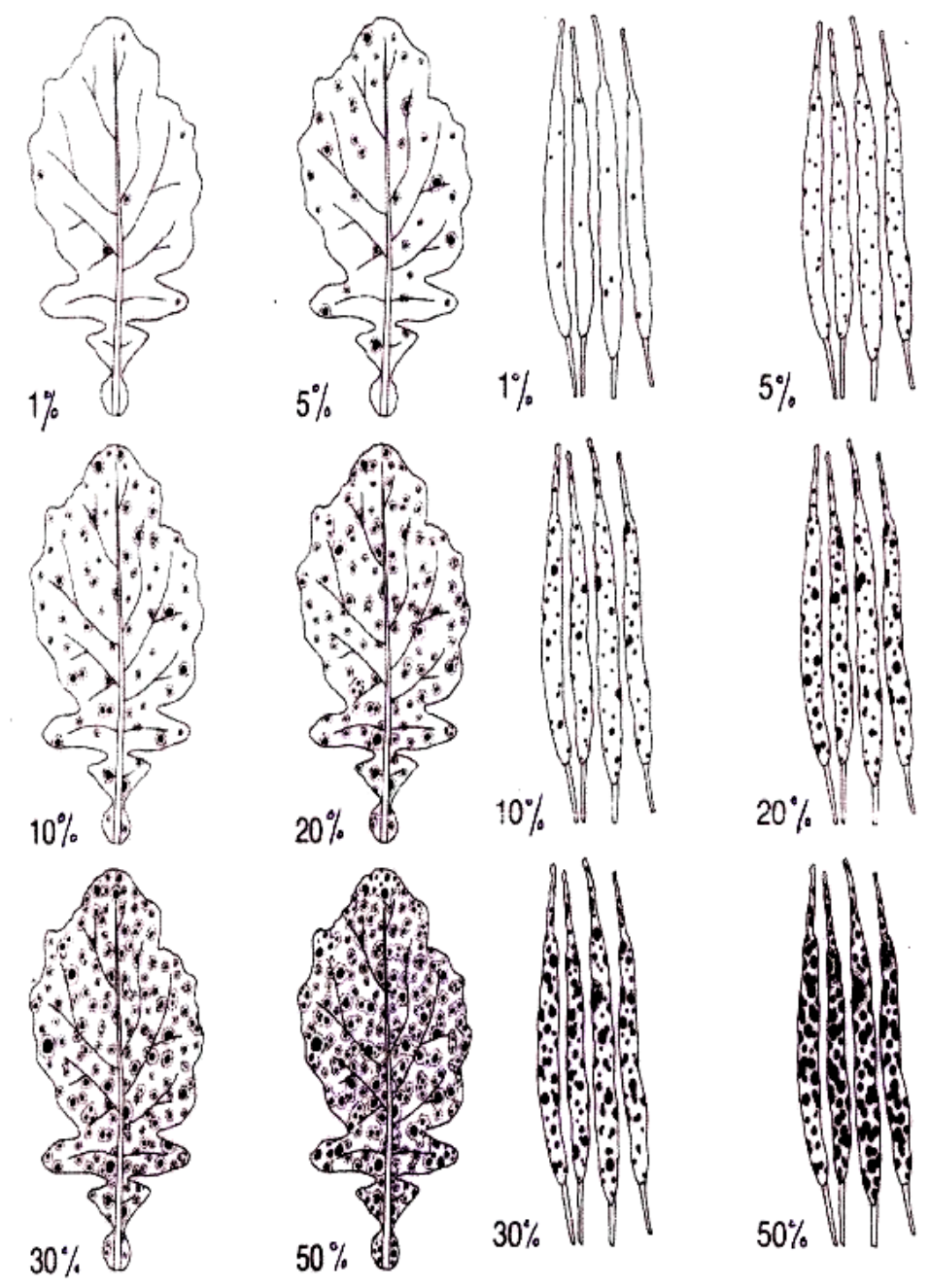

\begin{tabular}{|c|}
\hline Rating \\
\hline 0 \\
\hline 1 \\
\hline 2 \\
\hline 3 \\
\hline 4 \\
\hline 5 \\
\hline 6
\end{tabular}

6

\begin{tabular}{|c|}
\hline Leaf and Pod \\
\hline No infection \\
\hline Upto $5 \%$ area covered \\
\hline$>5-10 \%$ area covered \\
\hline$>10-20 \%$ area covered \\
\hline$>20-30 \%$ area covered \\
\hline$>30-50 \%$ area covered \\
\hline$>50 \%$ area covered \\
\hline
\end{tabular}

\begin{tabular}{|c|}
\hline Reaction \\
\hline I \\
\hline HR \\
\hline R \\
\hline MR \\
\hline MS \\
\hline S \\
\hline HS \\
\hline
\end{tabular}

Where, $\mathrm{I}=$ Immune, HR = Highly resistant, $\mathrm{R}=$ Resistant, $\mathrm{MR}=$ Moderately resistant, $\mathrm{MS}=$ Moderately susceptible, $\mathrm{S}=$ Susceptible and HS = Highly susceptible 


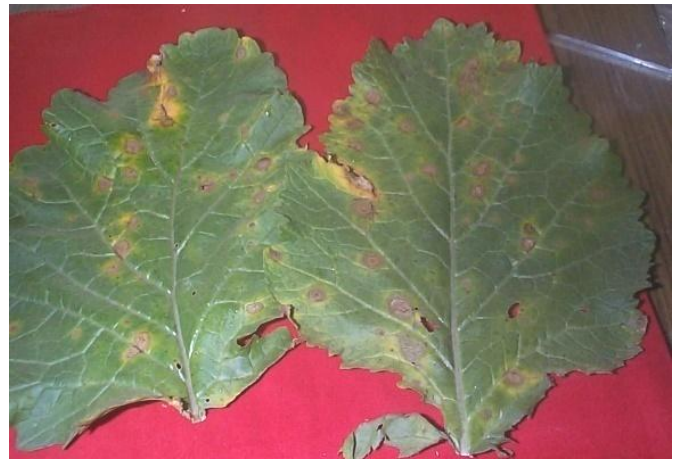

Plate 1. Symptoms of Alternaria blight on mustard leaves

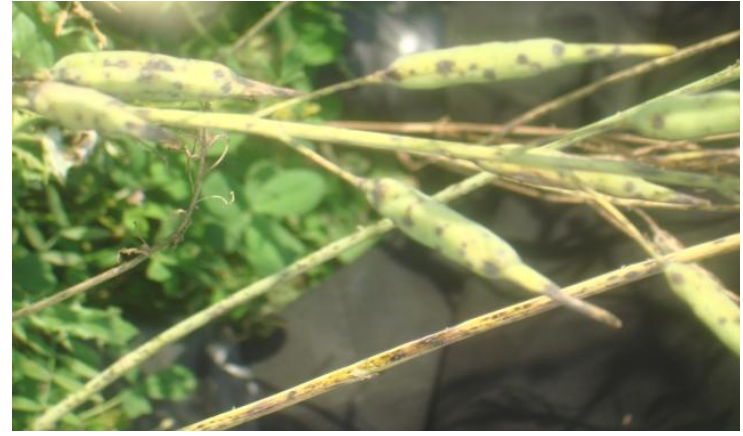

Plate 2. Symptoms of Alternaria blight on of mustard on pods

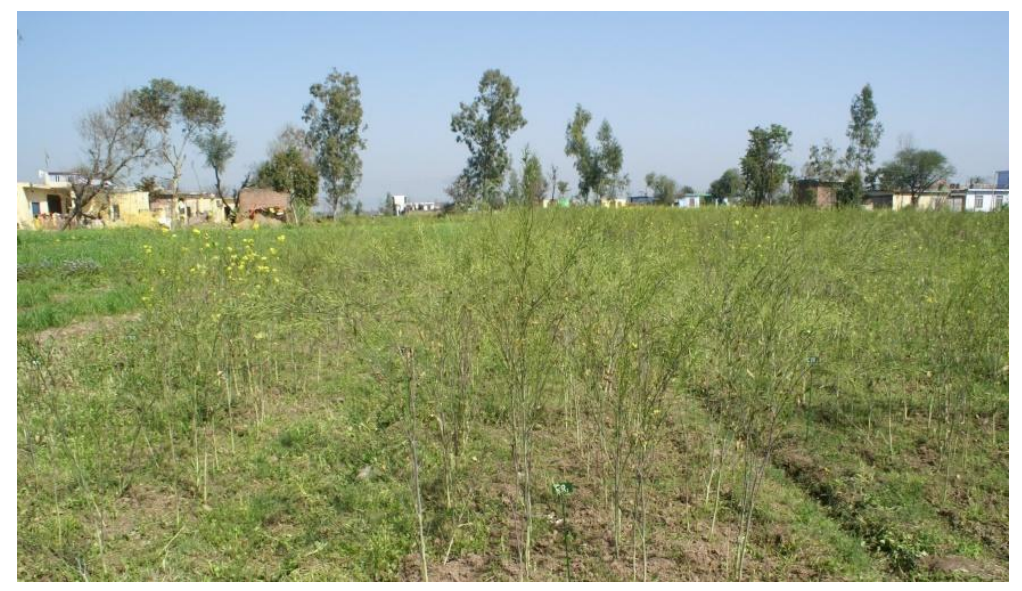

Plate 3.Field view of screening of germplasm of rapeseed-mustard.

Kadian and Saharan (1983) and Ram and Chauhan (1998) reported 15 to 71 per cent losses in rapeseed-mustard due to Alternaria blight. The disease is also reported to be of major economic importance in Australia, France, Poland and of moderate importance in Canada and United Kingdom (Barman and Bhagwati (1995). Hong and Fitt (1996) reported that Alternaria blight results into yield losses up to 71.4 per cent. Bharti et al., (2016) also observed the highest disease intensity of 53.60 per cent from Kalyanpur (Kanpur) and lowest intensity (37.60\%) was recorded from Bagha (Kanpur) during their survey of various locations. During extensive surveys, Gupta et al., (2017) found the maximum disease intensity $(44.13 \%)$ at Chatha while minimum disease intensity $(28.90 \%)$ was recorded from Gudwal area of Jammu Province.

For the successful establishment of Alternaria blight of rapeseed-mustard, the causal organism (Alternaria brassicae) requires low temperature, high humidity and splashing rain (Humpherson and Phelps, 1989). In India, maximum temperature of $27-28^{\circ} \mathrm{C}$, minimum temperature of $14-15^{\circ} \mathrm{C}$, average relative humidity more than 65 per cent, intermediate winter rains and wind velocity $2-5 \mathrm{~km} / \mathrm{hr}$ has 
been reported to be most conducive to Alternaria blight development in rapeseedmustard (Sangeetha and Siddaramaiah, 2007; Conn et al., 1990). Prevailing low temperature coupled with high humidity in Reasi and Udhampur may be the reason for increased severity of the disease in these districts. The pathogen is greatly influenced by weather with the highest disease incidence reported in wet seasons and in areas with relatively high rainfall (Meena et al., 2010). Alternaria blight of rapeseed-mustard has been reported to be predominantly seed borne (Parajuli, 2005). Thus, it seems that the disease problem has aggravated due to continuous use of infected local seed that has not been replaced for a number of years and no plant protection measures adopted at appropriate stages along with improper cropping practices being followed by farmers.

Twenty seven genotypes were procured from DRMR, Bharatpur and evaluated for their reaction towards Alternaria blight so as to screen out the germplasm resistant to Alternaria blight for this region. Observations for leaf and pod blight were taken at 75 and 100 DAS. During the experiment, it was found that out of all the genotypes screened, two genotypes viz. RH-8113 and PC-5 showed moderate resistance against the disease (>10-20\%) while four genotypes viz. GM-3, RH-1359, RH-819 and JM-1 showed moderate susceptibility (>20-30\%) and eighteen genotypes (Geeta, PusaBahar, Rohini, RH-30, Shivani, RH-781, RGN-13, GM-2, RRN-505, Krishna, GM-1, PusaJaganath, Vaibhav, RSPN-602, DGS-1, RSPN-25, RSPN-2 and RSPR-69) were found to be susceptible recording disease severity ranging from 30-50 per cent. Three genotypes viz. Kranti, Varuna and CS-54 showed high susceptibility and the disease severity was found to be more than 50 per cent (Table 2). Sources of resistance to the disease in Brassica napus and Brassica juncea have been listed by (Saharan et al., 1988) and the cultivar Prakash has been reported to be highly susceptible. It has been reported that genotypes viz. DIR-1507 and DIR-1522 of Brassica juncea had stable resistance against Alternaria blight (Dang et al., 2000). Fifty four lines/varieties in Alternaria sick plot were tested by Srivastava et al., (2001) and observed that none of the varieties was resistant to Alternaria blight. Among the various varieties tested by Mondal (2008) Jhumkta, Sanjuka, Aseech, Seeta and Bhagirathi were found to be better and could be recommended against the disease. The cultivars Binoy, Agrani, Panchali and SwamaSarisa showed more susceptible reaction against Alternaria blight than rest of the cultivars. Screening of sunflower genotypes to evaluate them for resistance to Alternaria helianthi was performed and it was found that the disease intensity for hybrids ranged from 3.73 to 52.33 per cent. RHA 587 and ARG x RHA 587 were found to be resistant to Alternaria blight both under field and laboratory conditions and therefore have the potential to reduce yield losses because of this disease in the field (Reddy et al., 2006). It can be concluded that use of germplasm which showed resistance to Alternaria blight during the present studies, can check the disease severity as well as the disease spread under Jammu conditions and thereby minimizing the losses incurred by farmers due to Alternaria blight of rapeseed-mustard.

Present studies were undertaken on Alternaria blight of rapeseed-mustard in order to determine the status of disease in Jammu Division, to screen germplasm of rapeseedmustard for resistance to Alternaria blight.

During the course of survey, the disease was found to be present at 75 and 100 DAS in all the districts. Maximum disease severity reported was 38.53 per cent in leaves and 32.72 per cent in pods at 75 DAS and 49.71 
per cent in leaves and 44.97 per cent in pods at 100 DAS which was observed in Reasi district. However, minimum disease severity i.e. 20.40 per cent and 11.30 per cent in leaves and pods respectively at 75 DAS and 32.97 per cent and 23.42 per cent in leaves and pods respectively at 100 DAS was observed in Samba.

The results of screening experiments of rapeseed-mustard germplasm revealed that out of twenty seven genotypes tested for disease reaction against Alternaria blight, two genotypes viz. RH-8113 and PC-5 were found to be moderately resistant at 75 and 100 DAS (>10-20\% disease severity), four genotypes viz. GM-3, RH-1359, RH-819 and JM-1 were found to be moderately susceptible (>20-30\% disease severity), eighteen genotypes viz. Geeta, PusaBahar, Rohini, RH-30, Shivani, RH-781, RGN-13, GM-2, RRN-505, Krishna, GM-1, PusaJaganath, Vaibhav, RSPN-602, DGS-1, RSPN-25, RSPN-2 and RSPR-69 were found to be susceptible recording a disease severity ranging from 30 to 50 per cent in leaves and pods. However, three genotypes viz. Kranti, Varuna and CS-54 were found to be highly susceptible to Alternaria blight ( $>50 \%$ disease severity) at 75 and 100 DAS.

\section{References}

Anita G and Gowthaman R 2003. Strategies for development of fungus- resistant transgenic plants. Current Science, 84: $3-10$.

Anonymous, 2007. Package of practices for Rabi Crops. pp. 26-29. Sher-e-Kashmir University of Agricultural Sciences and Technology Jammu, Jammu.

Anonymous. Agricultural statistics at a glance. 2009. Agriculture Statistics Division, Department of Agriculture and Cooperation, Ministry Agriculture, GOI, New Delhi
Anonymous. Digest of Statistics. 2008. pp. 110-116. Directorate of Economics and Statistics, Government of J \& K.

Anonymous. Agricultural statistics at a glance. 2014. pp 111-112. Agriculture Statistics Division, Department of Agriculture and Cooperation, Ministry Agriculture, GOI, New Delhi

Ansari NA, Khan MW and Muheet A 1988. Effect of Alternaria blight on oil content of rapeseed and mustard. Current Science, 57: 1023-1024.

Bains PS and Tewari JP 1986. Isolation and characterization of the toxin produced by Alternaria brassicae. Proceedings of Crucifer Genetic Workshop 3. 1986. pp. 66. University of Guelph, Canada.

Barman Band Bhagwati R 1995. Assessment of yield losses due to Alternaria brassicae in mustard. Plant Health, 1: 80-82.

Barnett HL and Hunter B 1972.Illustrated Genera of Imperfect Fungi.pp.128. Burgess Publishing Company, Minnea polis, Minnesota.

Bharti M, Prasad R, Kumar D, Kumar S and Kumar R 2016. Survey and Bioefficacy of Bio-agents against Alternaria brassicae causing Blight Disease of Mustard. Agriways, 4: 121-126.

Conn KL, Tewari JP and Awasthi RP 1990. A disease assessment key for Alternaria black spot in rapeseed and mustard. Canadian Plant Disease Survey, 70: 1990. 1.

Dang JK, Sangwan MS, Mehta N and Kaushik CD 2000. Multiple disease resistance against four fungal foliar diseases of rapeseed-mustard. Indian Phytopathology, 53: 455-458.

Gupta S, Singh VB, Singh AK, Rai, SK, Singh SK and Dwivedi MC 2017. Prevalence, incidence and management of Alternaria blight of Rapesee and mustard (Brassica juncea L) through resistance and integrated approach. 
International Journal of Current Microbiology and Applied Sciences, 6:2730-2741.

Hong CX and FittBDL 1996. Factors affecting the incubation period of dark leaf and pod spot (Alternaria brassicae) on oilseed rape (Brassica napus). European Journal of Plant Pathology, 102:545-553.

Humpherson JFM and Phelps K 1989. Climatic factors influencing spore production in Alternaria brassicae and Alternaria brassicicola. Annals of Applied Biology, 114: 449-458.

Kadian AK and Saharan GS 1983. Symptomology, host range and assessment of yield losses due to Alternaria brassicae infection in rapeseed mustard. Indian Journal of Mycology and Plant Pathology, 13: 319-323.

Kalyan K, Mondal RC, Bhattacharya KR, Koundal and Chatterjee, SC 2007. Transgenic Indian mustard (Brassica juncea) expressing tomato glucanase leads to arrested growth of Alternaria brassicae. Plant Cell Reproduction, 26: 247-252.

Kolte SJ 1985. Diseases of Annual Edible Oilseed crops. Vol. II, pp. 135. CRC Press, Inc

Meena PD, Awasthi RP, Chattopadhyay C, Kolte SJ, and Kumar A 2010.Alternaria blight: a chronic disease in rapeseedmustard. Journal of Oilseed Brassica.1: $1-11$.

Mondal G 2008. Evaluation of variety against Alternaria blight and Sclerotinia rot diseases of rapeseed-mustard for old alluvial zone of the Northern part of W. Bengal. Environment and ecology, 26: 2189-2191.

Parajuli GP 2005. Detection and management of seed-borne Alternaria brassicae in rapeseed and mustard. MSc. thesis.
Department of Plant Pathology, IAAS, Rampur, Chitwan, Nepal.

Ram RS and Chauhan VB 1998. Assessment of yield losses due to Alternaria leaf spot in various cultivars of mustard and rapeseed. Journal of Mycopathological Research, 36: 109-111.

Randhawa HS and Aulakh KS 1981.Pathology of shrivelled seeds of rapeseed and mustard in Punjab. Indian Phytopathology, 34: 318.

Rather TR 2005.Studies on the wilt complex disease of Capsicum annum. Ph.D. thesis, Sher-e-Kashmir University of Agricultural Sciences, Jammu.

Reddy CVCM, Reddy AVV, Sinha B and Lakshmi MS 2006.Screening of sunflower genotypes for resistance against Alternaria blight. Asian Journal of Plant Sciences, 5: 511-515.

Saharan GS 1992. Management of rapeseed and mustard diseases. pp. 155-188. In: Kumar, D. and Rai, M. (eds.). Advances in oilseed research. Vol. I, Rapeseed and mustard, Scientific Pub. Jodhpur.

Saharan GS and Mehta N 2002. Fungal diseases of Rapeseed-Mustard. In: Gupta, V. K. and Paul, Y. S. (eds.). Diseases of field crops. pp. 193-228. Indus Publishing Co, India.

Saharan GS, Mehta N and Sangwan MS 2003. Nature and mechanism of resistance to Alternaria blight in rapeseed-mustard system. Annual Review of Plant Pathology, 2: 85-128.

Saharan MS, Kaushik JC and Kaushik 1988. Source of resistance and epidemiology of white rust of mustard. Indian Pytopathology, 41: 96-99.

Sangeetha CG and Siddaramaiah AL 2007. Epidemiological studies of white rust, downy mildew and Alternaria blight of Indian mustard (Brassica juncea (Linn.) Czern. And Coss.). African journal of Agricultural Research, 2: 305-308. 
Srivastava MP, Mehta N, Sangwan MS and Kumar R 2001. Evaluation of Brassica varieties for resistance to Alternaria brassicae (Berk.) Sacc. Under epidemic conditions. Tests Agro. Cultivars, pp. 22.

Verma PR and G. S. Saharan Monograph on Alternaria diseases of crucifers.
Saskatoon Research Station Technical Bulletin. 1994 pp. 162.

Vishunavat K and Kolte SJ 2008. Essentials of Phytopathological Techniques, pp. 30-33. Kalyani Publishers, Ludhiana, New Delhi.

\section{How to cite this article:}

Baby Summuna, Sachin Gupta and Sheikh, P.A. 2018. Assessing the Disease Severity of Alternaria Blight of Rapeseed-Mustard in Jammu Province of J\&K and Screening of Germplasm against the Disease. Int.J.Curr.Microbiol.App.Sci. 7(11): 1299-1310.

doi: https://doi.org/10.20546/ijcmas.2018.711.151 